\title{
LAUDATIO
}

\section{SESSÃO DA CONGREGAÇÃO DA FAFICH/UFMG PARA CONCESSÃO DO TÍTULO DE PROFESSOR EMÉRITO AO PROF. JOSÉ HENRIQUE SANTOS E OUTRAS COLEGAS*}

Ivan Domingues (UFMG)

É com imensa satisfação que saúdo José Henrique Santos, mestre de toda uma geração e de muitos de nós aqui presentes, em sua segunda volta à Universidade, ontem como Titular hoje como Professor Emérito.

José Henrique já foi homenageado pelo Departamento de Filosofia em outra oportunidade, testemunhando o apreço e carinho que temos por ele coisa que ele sabe de há muito e cujo veículo e símbolo que lhes deu vívida expressão ele guarda em sua biblioteca, assim como num canto da memória. Estou me referindo à Festchrift em sua homenagem, da qual juntamente com Paulo Margutti e Rodrigo Duarte fui um dos organizadores e a qual foi publicada em 2002, pela Editora UFMG, com o título de Ética, política e cultura. Trata-se de uma coletânea de textos que lhe foi oferecida por um conjunto de colegas e amigos de vários pontos do país com a simples intenção de homenageá-lo, em sinal de reconhecimento daquilo que José Henrique tinha feito e vem fazendo pela filosofia em nossos meios. E o que é importante: uma homenagem longe de datas cabalísticas e das melancólicas ocasiões das compulsórias, como foi escrito na ocasião na Introdução do livro, e isto para melhor evidenciar que se tratava de uma homenagem, nada mais, fruto do reconhecimento dos amigos e sinal do apreço e carinho que sentimos por ele.

* Cerimônia de entrega do título de professor emérito da UFMG ao professor José Henrique Santos.

KRITERION, Belo Horizonte, nº 121, Jun./2010, p. 293-297. 
Hoje, passados sete anos, estamos às voltas com uma nova homenagem a José Henrique, uma homenagem em que o motivo é diferente, mas é o mesmo o sentido. Diferente porque não estamos celebrando a permanência, mas a volta, conferindo um título que é uma das maiores honrarias que as universidades podem oferecer. $\mathrm{O}$ mesmo porque não estamos reconhecendo propriamente algo novo ou homenageando alguém estranho ou diferente, mas celebrando o mesmo mestre, mestre que a aposentadoria afastou de nós, mas que queríamos que voltasse. Agora José Henrique está de volta, e eu aqui perto dele e de Ângela.

Há quase quarenta anos conheço e fui aluno de José Henrique, nos tempos da velha FAFICH da Rua Carangola, no oitavo andar do prédio construído por Arthur Versiani Velloso, mestre de José Henrique, fundador da Faculdade e um dos heróis-fundadores da filosofia no Brasil, ao lado de Fiori no Sul, Cruz Costa em São Paulo e Padre Penido e Álvaro Vieira Pinto no Rio de Janeiro. Do Departamento atual, depois de tantas aposentadorias, somos poucos os elos entre a geração atual dos professores saída da casa e, digamos, a velha guarda da Carangola, representada aqui hoje por José Henrique. Passados esses quarenta anos, o Departamento mudou muito, ao deixar para trás a época heroica da fundação e chegar aos tempos atuais da expansão e consolidação, mas - acredito eu - guardou o compromisso com o espírito da filosofia, ensinado pelos mestres.

Dois são os depoimentos e duas as considerações que eu gostaria de fazer. Primeiro, na qualidade de aluno; segundo, na qualidade de colega do homenageado.

Fui aluno várias vezes de José Henrique na velha FAFICH em seus cursos de história da filosofia moderna, sobre a fenomenologia de Husserl e a Crítica da razão pura de Kant. Eu me lembro até hoje de suas aulas, em que ele com voz mansa e passos lentos ia para lá e para cá, discorrendo sobre temas de história da filosofia, da ciência e da cultura, com penetração filosófica, grande erudição e pensamentos límpidos. Foi nesta ocasião que eu descobri que os cascalhos do norte de Minas onde José Henrique nasceu já escondiam o diamante, como eu disse na Festschrift.

Penso que do Departamento onde estudei, além da amizade de Bicalho, e a quem o saudei como emérito um dia, José Henrique foi o professor que mais admirei e um dos que mais marcas deixaram em mim, coisa que descobri aos poucos e que foi se sedimentando com o passar dos anos.

Passada a época de estudante, fui colega de José Henrique por muito tempo e pude testemunhar de perto, em diferentes momentos da história da instituição, a sua aderência institucional ao Departamento e à Universidade, 
bem como a sua liderança intelectual nos diferentes planos da vida acadêmica, evidenciadas ambas as qualidades nos cargos que ocupou e nas comissões de que fez parte, dentro e fora da Universidade.

Assim, na chefia e nas atividades de coordenador do curso, em meio às ameaças dos anos de chumbo em que a filosofia e as ciências humanas não tinham voz nem vez, José Henrique com clarividência e empenho apontou o caminho para um Departamento amedrontado, receoso de seu futuro: o caminho de espraiar-se pela Universidade, mostrando seu rosto em diferentes faculdades e se expondo ao maior dos desafios, onde poderia soçobrar, se perdesse a aposta, ou sair fortalecido, se vencesse. Trata-se, como disse o colega Ricardo na Festschrift, do desafio da alteridade, experienciado acrescento eu - ao decidir se expor ao olhar e ao questionamento do outro - ao olhar da ciência, da tecnologia e das artes, e do outro muitas vezes desconfiado e nada acolhedor das esquisitices filosóficas. O resultado é conhecido: o Departamento venceu e a filosofia saiu-se fortalecida, primeiro com a criação do Ciclo Básico em Ciências Sociais tendo-nos como um dos parceiros, depois com a implantação da pós-graduação, nos anos 1970 o mestrado, nos anos 1990 o doutorado. Hoje a situação mudou, e muito: não é mais o tempo de espraiar e de mostrar o rosto, mas de se recolher e de adensar a experiência acumulada, cuidando da pesquisa, da produção acadêmica e dos diferentes níveis do ensino, com a nossa graduação rankeada entre as melhores do Brasil e a pós a ocupar o posto das três grandes.

Em tudo isso, não é exagerado dizer, tem as mãos e a mente de José Henrique. E mais ainda: não só no Departamento, que era e é o seu lugar natural, mas suas marcas estão também na Administração central, nos cargos que exerceu, de vice-reitor e reitor, numa época difícil, em plena ditadura militar, com a Universidade exposta às truculências do regime de força, mas contra as quais o Reitorado e José Henrique souberam resistir, preservando aquilo que é o patrimônio de todos e o bem maior da civilização: o conhecimento e a cultura.

A envergadura e a importância das atividades de José Henrique não tardaram em ser reconhecidas, dentro da Universidade ou intramuros, e fora da Universidade ou extramuros. Tal é o caso da Festschrift já mencionada, a primeira em Minas Gerais; tal é o caso de sua eleição para a presidência da ANPOF e para a coordenação da área de filosofia do CNPq, ambos de suma importância para a nossa comunidade; e tal é o caso, enfim, da sua indicação para a Academia Mineira de Letras, onde ele ocupa a cadeira que foi de Arthur Versianni Velloso e em claro reconhecimento de seus dons literários, a julgar 
pelo conjunto dos seus escritos, com a sua prosa encantadora e o seu estilo admirável.

Ao dizer isso, toco no último ponto de meu depoimento, como colega e leitor dos escritos de José Henrique, focalizando suas qualidades intelectuais. Por uma questão de tempo, vou me limitar aos livros que ele escreveu e fazer uma breve menção a alguns dos artigos que ele publicou.

Três são os livros. O $1^{\circ}$ deles, na origem sua tese de doutorado, com uma primeira edição em Braga, Portugal, e uma segunda, revisada e ampliada, em preparação pela Loyola, devendo sair ainda neste ano, em comemoração aos 150 anos de Edmund Husserl e objeto do livro, cujo título será ligeiramente alterado: Do empirismo à Fenomenologia - a crítica do psicologismo nas Investigações lógicas de Husserl. O segundo é Trabalho e riqueza na Fenomenologia do espírito de Hegel, livro notável que em sua origem foi a tese de titular de José Henrique e posteriormente publicada com pequenas modificações pela Loyola em 1993. O terceiro saiu em 2007 e é, como ele me confessou, o preferido dele: trata-se de $O$ trabalho do negativo: ensaios sobre a Fenomenologia do espírito, livro magnífico que meu amigo Hugo Amaral aqui presente, e como eu admirador dos escritos de José Henrique, sem exagero compara à leitura que Kojève fez de Hegel. Não literalmente igual a Kojève, com efeito, pois José Henrique explora outros temas e se vê diante de desafios diferentes, num livro em que expressa mais uma vez seu enorme talento filosófico e seu apurado requinte de escritor. O resultado é uma obra que não é meramente exegética ou interpretativa, mas uma obra pessoal que pensa com e contra Hegel, sua paixão madura e tardia, e procura trazê-lo para a atualidade, enfrentando temas ligados à cultura, ao conhecimento, à religião, à política e à própria filosofia.

Dentre os artigos eu citaria "O lugar da crítica na Faculdade do juízo na filosofia de Kant", assim como o "Assalto à razão administrada", escrito em homenagem a Raul Landim e a Guido de Almeida, e ainda, de um modo especial, "Brava gente brasileira: pequeno ensaio sobre a sociedade e o Estado por ocasião do V centenário". Dos três, este é no meu modo de ver uma das melhores coisas que José Henrique escreveu e onde ele nos fornece uma das suas contribuições mais originais, desta feita para pensar o nosso país, a nossa cultura e a nossa gente, desmentindo a ideia de que o filósofo é um alienado que vive trancado na torre de marfim.

Concluo então dizendo que, além de diamante lapidado com o passar do tempo, depois de trocar os ares de Paracatu pelos de Belo Horizonte, José Henrique é um intelectual de boa e velha cepa, um intelectual à antiga que viaja e produz relativamente pouco, mas quando produz e publica alguma coisa é 
como se fosse um verdadeiro diamante. Intelectual generoso, comprometido com a instituição, de horizontes largos e vasta envergadura intelectual, o nosso emérito, ao lado de outros como Vaz e Bicalho, é o antípoda do pesquisador solo com sua carreira egoica e calculista, demonstrando que o mais apurado dos dons intelectuais pode ir junto com o mais diligente cuidado com o outro, aluno ou colega, e a mais constante das abnegações para cuidar da coisa pública. Que sua volta ajude o Departamento e a Universidade a repensarem a carreira e a reencontrarem o rumo, como na Rua Carangola há quarenta anos. Que seu exemplo tenha uma boa acolhida entre nós, finque raízes e frutifique. Em nome do Departamento, neste momento especial, as nossas boasvindas.*

* Depois da solenidade, em conversa com José Anchieta Corrêa, professor aposentado do Departamento, vim a saber de um fato biográfico importante ligado à formação acadêmica de José Henrique e que não fora mencionado nem no Festschrift nem em minha saudação. Este episódio aguçou minha curiosidade por um motivo anedótico envolvendo uma figura ilustre, e do sertão das Minas, como Ângela e José Henrique. A figura ilustre é Guimarães Rosa, que era do Itamaraty e que intercedeu em favor do casal, levando o Ministério a suplementar a bolsa do DAAD e, assim, aliviando os dois das dificuldades pelas quais passavam em terras estrangeiras. Tempos depois procurei José Henrique para conversar sobre o episódio, quando descobri coisas importantes a respeito e as quais eu gostaria de registrar em apêndice à Laudatio. Ao fazê-lo, minha intenção é preservar a memória de uma época em que poucas eram as oportunidades de alguém fazer estudos de pós-graduação no exterior, sendo justamente um desses raros agraciados o nosso emérito.

Estimulado pelo Prof. Velloso, José Henrique decidiu fazer seu doutorado na Alemanha. Fez então uma espécie de concurso e obteve do DAAD (Serviço Alemão de Intercâmbio Acadêmico) uma bolsa. Ele foi não apenas o único escolhido em Minas, mas a concessão foi o primeiro caso em Minas Gerais e um dos primeiros no Brasil. O valor da bolsa era de 500 marcos mensais, muito pouco segundo ele. Ele e Ângela viviam com muita dificuldade. Foi então que eles procuraram o Itamaraty, e foi aí que Guimarães intercedeu. O Itamaraty concedeu um pequeno auxílio semestral de 200 marcos, o que, dividido por seis meses, significava um acréscimo de mais ou menos 33 marcos por mês. Não era uma fortuna, mas de qualquer modo os ajudou a vencer aqueles tempos difíceis.

Anos depois, as bolsas do DAAD se multiplicaram, os valores aumentaram, a CAPES e o CNPq entraram em cena e a situação dos estudantes melhorou. Mas não na época dele e de Ângela.

José Henrique defendeu sua tese mais tarde, na UFMG. 